\title{
ROLE OF ACID HYDROLYSIS BEHAVIOR ON STRUCTURE AND DEPOLYMERIZATION OF LIGNIN EXTRACTED FROM RICE STRAW
}

\author{
Sumit Sharma ${ }^{1}$, Saurabh Jyoti Sarma ${ }^{1^{*}}$ \\ ${ }^{1}$ Department of Biotechnology, Bennett University, Greater Noida, (U.P.), India
}

\begin{abstract}
Chemical reactions mostly have a dependency on catalyst concentration. Sometimes, the action of higher concentration enhances the rate very high that disrupts the product appearance and structural integrity. It is also applicable for biological material degradation. Here in this study, the degradation of rice straw biomass was executed for lignin extraction using the acid hydrolysis treatment method. This technique helps in the removal of maximum cellulosic parts like cellulose and hemicellulose by converting them into soluble sugars and remains left out lignin. It was investigated that the higher concentration of sulfuric acid as $72 \% \mathrm{v} / \mathrm{v}(80.77 \% \mathrm{w} / \mathrm{w})$ caused some structural changes in chemical bonds and formed highly condensed lignin (L-72). While mild concentration of sulfuric acid $63 \% \mathrm{v} / \mathrm{v}(72.26 \% \mathrm{w} / \mathrm{w})$ does not have any adverse effect on lignin structural integrity and was found as free-form lignin (L-63). The impact of condensation was observed during the depolymerization of L-72 and L63. The depolymerization efficiency of L-72 and L-63 in alkaline medium $(\mathrm{NaOH}$ $1.5 \%$ and Na2S 0.5\%) comparatively lesser for L-72 (34\%) than L-63 (98.3\%) using lignin $2 \mathrm{~g} / \mathrm{l} . \mathrm{FT}$-IR analysis also showed the presence of CO-O-CO (anhydride) and $\mathrm{C}=\mathrm{C}$ (alkenes) in condensed lignin but not found in free-form lignin. This means the structural condensation decreasing the depolymerization efficiency of lignin. Hence, it is concluded that free-form, light- brown lignin should be used for depolymerization and monolignolextraction.
\end{abstract}

\author{
Keywords \\ Acid hydrolysis, Condensed \\ Lignin, Free-form lignin, \\ Depolymerization
}

\section{Introduction}

Lignin waste management and depolymerization is the major challenge facing by cellulosic refinery and wood pulp industries [1, 2]. Solid remaining lignin is becoming the major waste there. Lignin utilization as a simple source is difficult due to its polymeric structure that is made up of aromatic rings [3]. These rings are divided into 3 kinds of aromatic alcohols (sinapyl, coniferyl, and coumaryl forms) bound by aryl-ether bonds. These bonds are not easily breakable by the acid treatment process used recently in biorefineries to obtain higher cellulosic sugar yield [4]. The lignin generated from these treatments is a phenolic complex [5] and its depolymerization depends on structural integrity. The depolymerization rate is directly linked with the extent of lignin complexity. If it is too high, the bond breakage is very difficult and needs a higher temperature with a catalyst [6]. More complex means condensed lignin and less complex simpler form can be called free-form lignin. For complete hydrolysis of sugar, a higher concentration of acid can be used but it may de-hydrate the other reactive compound and condensed them into the structure. This causes difficulty in further degradation of lignin into a product. The use of this abundant waste requires a simpler process for its treatment such as depolymerization. Alkaline-based depolymerization is a way to convert into monomers [7]. While due to high complexity, the access of alkaline functional components such as -OH and - $\mathrm{SH}$ group to oxidize the lignin into simple monomers become unavailable and the free space, as well as action site, closed inside the complex [8]. The nucleophilic attack of the functional group of solvent is only accessible to 
the outer surface and the inter-bound aryl-ether bonds become inaccessible $[8,9]$. This directly affects the decrease in the rate of depolymerization of lignin. Here in this study, the effect of acid concentration on lignin extraction from rice straw biomass and its depolymerization challenges are focused. It is also attempted to find out how structural complexity plays role in lignin de-polymerization efficiency.

\section{MATERIALS AND METHODS}

Dry biomass of rice straw was collected from the region of Mohna, Ballabgarh, Faridabad, Haryana. All the chemicals used in this study have been procured from SRL chem. This study used the methodsexplained in further sub-sectionsfor identifying the role of acid hydrolysis on the lignin extraction, depolymerization.Along with that, substrate value optimization and structural analysis has also been done for validation of the comparative outcomes.

\section{Condensed and free-form lignin extraction from rice straw}

Rice straw lignin was extracted by usinga method developed by Sluiter et al. (2008) [10] along with two different concentrations of sulfuric acid $80 \% \mathrm{w} / \mathrm{w}$ and $72 \% \mathrm{w} / \mathrm{w}$. The method was followed as: rice straw was subjected to acid solutions in a 1:10 ratio and kept for incubation for 60 minutes at $30^{\circ} \mathrm{C}$ at $150 \mathrm{RPM}$. After incubation, diluted to $4 \%$ by calculating the dilution in v/v forms: $72 \% \mathrm{v} / \mathrm{v}=80.77 \% \mathrm{w} / \mathrm{w}$ ) and $63 \% \mathrm{v} / \mathrm{v}=72.26 \% \mathrm{w} / \mathrm{w}$. Both the mixtures were autoclaved at $121^{\circ} \mathrm{C}$ for 30 minutes at 15 psi. After cool down, the solid was separated from the liquid by centrifugation at $8000 \mathrm{rpm}$ for 10 minutes at $25^{\circ} \mathrm{C}$. The solid pellet was washed 2 times with distilled water (DW) and then dried at room temperature (RT) for 24-48 hours for complete drying of the solid. The solid material was weighed to find out lignin percentage and then stored in glass vials at room temperature for further use. Different parameters like the appearance of color; texture and solubility in water were investigated.

\section{Depolymerization of condensed and free-form lignin}

De-polymerization of both types of lignin was done with an alkaline solution of $\mathrm{NaOH}(1.5 \%)$ and $\mathrm{Na}_{2} \mathrm{~S}(0.5 \%)$. This combination of Solution for Chemical-bond Breakagewas named SCB. 2g/l of L-72 and L-63 were mixed with SCB in two sets of temperatures: $30^{\circ} \mathrm{C}$ and $80^{\circ} \mathrm{C}$. Both the combinations were incubated at both temperatures (in triplicates) for 60 minutes, mixed after every 10 minutes. After incubation, removed from respective specific temperatures and kept for settling at RT for 1 hour. The liquid was removed by pipetting and subjected to neutralization by $1 \mathrm{M} \mathrm{H}_{2} \mathrm{SO}_{4}$ to nearly $\mathrm{pH} 7-8$. and the solid was washed 2 times with DW. The Solid-water mixture was washed and separated bycentrifugation at 8000 RPM for 10 minutes at RT and dried at RT for 12 hours and dried remaining lignin was weighed for calculating depolymerization efficiency.
Substrate concentration optimization near to maximum rate

The substrate concentration optimization was done with L-63 ranges from $1 \mathrm{~g} / \mathrm{l}$ to $5 \mathrm{~g} / \mathrm{l}$ in duplicates with SCB. The experiment was done in $30 \mathrm{ml}$ screw-cap glass vials with 10 $\mathrm{ml}$ working volume. The mixture was incubated at $30^{\circ} \mathrm{C}$ for 60 minutes at 150 RPM.A similar experiment was done with $\mathrm{L}-63$ from $0.5 \mathrm{~g} / \mathrm{l}$ to $2.5 \mathrm{~g} / \mathrm{l}$ values at $30^{\circ} \mathrm{C}$ for identifying the closest substrate value. After incubation, depolymerization efficiency was estimated by a similar procedure applied before.

\section{FT-IR analysis for the structural integrity of L-72 and L- 63}

Fourier transform infrared (FT-IR) spectrum analysis was done for identifying the carbon bond stretching and bending which represents the structural complexity of a compound. L72 and L-63 extracted fine powder samples were placed on the sample platform on the FT-IR spectrometer (PerkinElmer Spectrum Two $\left.{ }^{\mathrm{TM}}\right)$. The sample was scanned using the software Spectrum 10 at 400 to 4000 wave number $\left(\mathrm{cm}^{-1}\right)$ for estimating transmittance. Firstly, a background blank was run to normalized all the background noise. Then, samples were run for extracting transmittance in percentage with respect to wave number from 400 to $4000 \mathrm{~cm}^{-1}$. The comparison profile of inter-linkage bonds was analyzed after plotting a graph between wave number $\left(\mathrm{cm}^{-1}\right)$ vs transmittance (\%).

\section{RESULTS AND DISCUSSION}

Condensed vs Free-form lignin characteristics

The condensed and free-form lignin extracted with two different concentrations of sulfuric acid showed a great impact on their product formation. The condensed lignin formed by $80 \%$ sulfuric acid (w/w) was dark brown in appearance while free-form formed by $72 \%$ sulfuric acid (w/w) was light brown. A high dense weight L-72 and lightweight L-63indicated that as the concentration of acid increases the condensation of lignin increases and structure became more complex and denser. Xu et al. (2006), also found an increase in condensation of lignin with an increase of organic acid in wheat straw pre-treatment [11] and the reason behind this was an increase of guaiacol units in biomass. It was also proposed by Sannigrahi et al. (2011) that condensation at higher acid leads to the production of pseudolignin [12] and enhances the complexity. At higher acid catalysis, dehydration of sugars generates furans, and these furans ties with aromatic precursors of lignin resulted in highly condensed polymeric lignin [4]. L-72was observed asa highly condensed form of lignin. L-72 and L-63 comparison at different parameters is illustrated in Table 1. The texture was observed asrough and hard for L-72 whereas smooth and soft for L-63. When solubility was tested in water, it was found that both are insoluble in distilled water. 
The final weightof both the lignin was nearly similar to 30$32 \%$ ofthe total dry weight of rice straw biomass, so there was a negligible difference in loss of solid lignin during acid treatment (Table 1). But the condensation of lignin was observed at a higher acid concentration of $80 \% \mathrm{w} / \mathrm{w}$ and freeform lignin at a slightly low concentration of $72 \% \mathrm{w} / \mathrm{w}$. Figure 1 depicted the visible appearance of both types of lignin. The surface area on visual appearance was also observed lowerfor condensed lignin than free-form lignin when a similar amount of lignin was valuedin mass. After all the comparative analysis, it was found that the L-63 is actual lignin that can be used further for depolymerization and monolignol extraction, while the comparative depolymerization study was done with both kinds of lignin to validate their structural complexity.

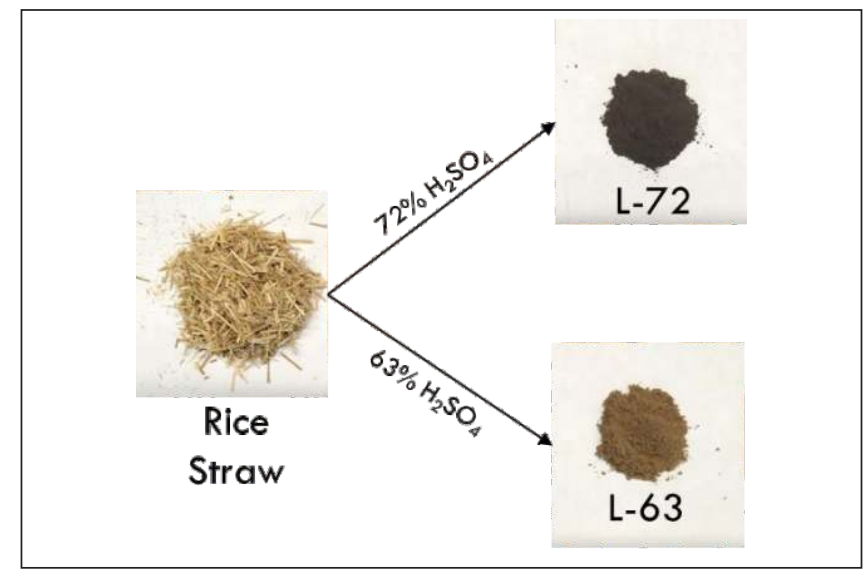

Figure 1: Condensed (L-72) and free-form (L-63) lignin extracted from rice straw by acid hydrolysis.

Table 1: Comparison between L-72 and L-63 at different parameters.

\begin{tabular}{|l|l|l|l|}
\hline Sr. No. & $\begin{array}{l}\text { Different } \\
\text { Parameters }\end{array}$ & L-72 & L-63 \\
\hline 1 & Color & Dark brown & Light brown \\
\hline 2 & Texture & Rough & Smooth \\
\hline 3 & Density & High & Low \\
\hline 4 & $\begin{array}{l}\text { Solubility in } \\
\text { water }\end{array}$ & Insoluble & Insoluble \\
\hline 5 & Lignin (\%) & $31 \pm 1$ & $31 \pm 1$ \\
\hline 6 & $\begin{array}{l}\text { Visible Surface } \\
\text { area }\end{array}$ & Small & Large \\
\hline
\end{tabular}

The rate of depolymerization of both the lignin was identified by treating with previously optimized alkali SCB: Sodium hydroxide $(\mathrm{NaOH}): 1.5 \%$ and Sodium sulfide $\left(\mathrm{Na}_{2} \mathrm{~S} . \mathrm{xH}_{2} \mathrm{O}\right)$ $0.5 \%$ - treatment based process for lignin (data not shown). The 2g/l of L-72 treated with SCB showed very less depolymerization at both the temperature $30^{\circ} \mathrm{C}$ and $80^{\circ} \mathrm{C}$ as compared to L-63 in both the conditions. A step-wise schematic representation for the process was also given in Figure 2. The dense form of L-72 does not show proper dissolution in an alkaline medium while the free-form L-63is easily dissolved in it. It was found that L-63 de-polymerized $88.3 \%$ at $30^{\circ} \mathrm{C}$ and $98.3 \%$ at $80^{\circ} \mathrm{C}$, while $\mathrm{L}-72$ depolymerized $30 \%$ at $30^{\circ} \mathrm{C}$ and $34 \%$ at $80^{\circ} \mathrm{C}$ (Figure 3). The effect of $\mathrm{pH}$ neutralization was observed by the formation of precipitate while lowering the $\mathrm{pH}$ to near 7 (Figure 4). The L63 at $30^{\circ} \mathrm{C}$ showed no precipitation after neutralization while a white precipitate was formed at near $\mathrm{pH}$ 7-8 in other samples. This showed that the L-63 does not show coagulation of free monolignols into precipitated lignin when $\mathrm{pH}$ reached near neutralization. Generally, reaction with acid causes phenolic group protonation [13] leads to the coagulation and precipitation of free monolignol of lignin. The acid precipitation process is used in paper industries for lignin recovery[14]. Mostly, lignin recovery from industry pulp liquor was done by reducing $\mathrm{pH}$ lower than 7 by the addition of acid [15]. In this case, ML (Monolignols; shown in Figure 4) of L-63 at $30^{\circ} \mathrm{C}$ is fairly stable at near neutral $\mathrm{pH}$ $\&$ and can be further proceeded to separate monomer purifications.

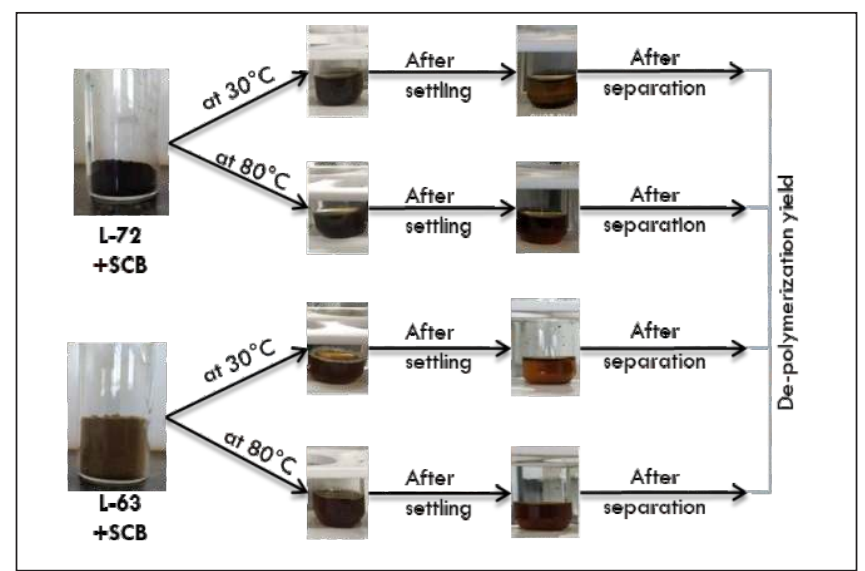

Figure 2: Step of L-72 and L-63 de-polymerization at two different temperature with $2 \mathrm{~g} / \mathrm{l}$ of lignin in SCB.

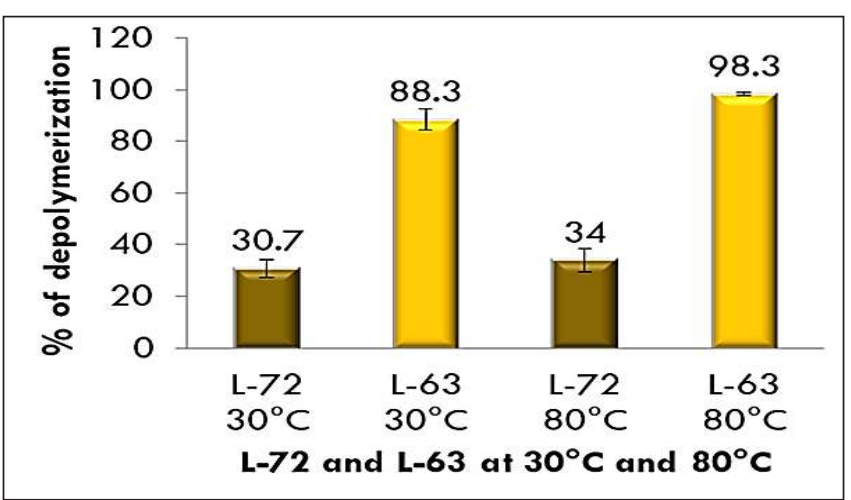

Figure 3: L-72 and L-63 depolymerization efficiency estimations at $30^{\circ} \mathrm{C}$ and $80^{\circ} \mathrm{C}$. 


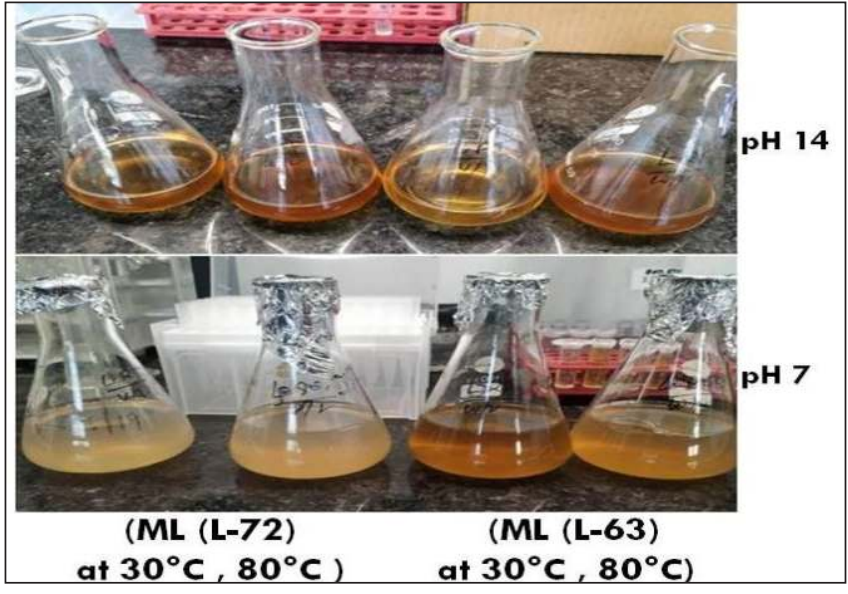

Figure 4: Effect of pH on L-72 and L-63.

\section{Substrate optimization of higher range L-63}

It was verified from the above experiment that the L-63 is better than L-72. Then, the maximum L-63 depolymerization with SCB was optimized at the higher range of L-63 concentration from $1 \mathrm{~g} / \mathrm{l}$ to $5 \mathrm{~g} / \mathrm{l}$. After depolymerization reaction, it was found that the $1 \mathrm{~g} / \mathrm{l}$ and $2 \mathrm{~g} / \mathrm{l}$ of L-63 depolymerized completely near $85 \%$ at $30^{\circ} \mathrm{C}$, but when concentration increased $3 \mathrm{~g} / \mathrm{l}$ to $5 \mathrm{~g} / \mathrm{l}$ depolymerization efficiency was $<70 \%$ (data not shown). So that further experiment was done to find out near maximum value and reproducibility of L-63. The range from $0.5 \mathrm{~g} / \mathrm{l}$ to $2.5 \mathrm{~g} / \mathrm{l}$ of L-

\section{FT-IR interlinkages in L-72 and L-63}

The FT-IR plot curve depicts the significant difference in the interlinking bonds between the L-72 and L-63 structural characteristics. It was found that the L-72 lignin sample consists of CO-O-CO (anhydride) and $\mathrm{C}=\mathrm{C}$ (alkene) stretching and more carbon-carbon bond [16]showed the
63 was evaluated for depolymerization efficiency using SCB. It was found that all the values have more than $80 \%$ depolymerization efficiency at temperature $30^{\circ} \mathrm{C}$ (Figure 5). It concludes that a higher substrate value of $2 \mathrm{~g} / \mathrm{l}$ of $\mathrm{L}-63$ can be used for depolymerization into monolignols and further purification of different phenolic monomers.

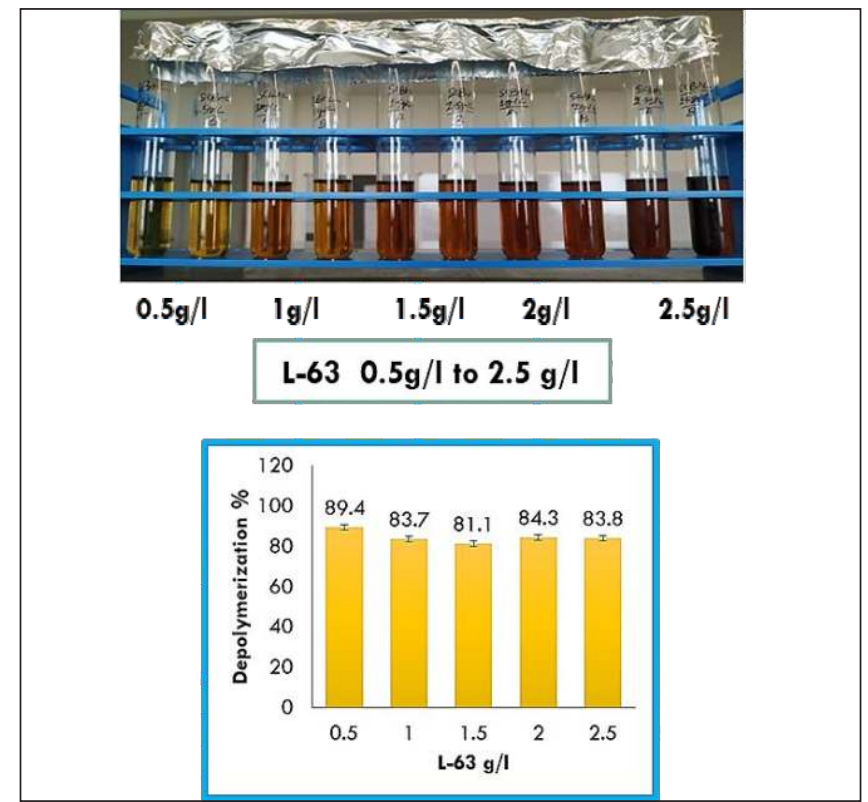

Figure 5: Substrate optimization for L-63 at different concentration of lignin in SCB.

lignin interlinkages. While, in L-63, there were simple C-O and $\mathrm{C}=$ Ostretching were found which showed the free form of the lignin structure (Figure 6). Remil et. al (2014) also found that the position of lignin falls into a similar range of wave number between $1700-1300 \mathrm{~cm}^{-1}$ as the maximum number of carbon bond stretching are found in this study at same

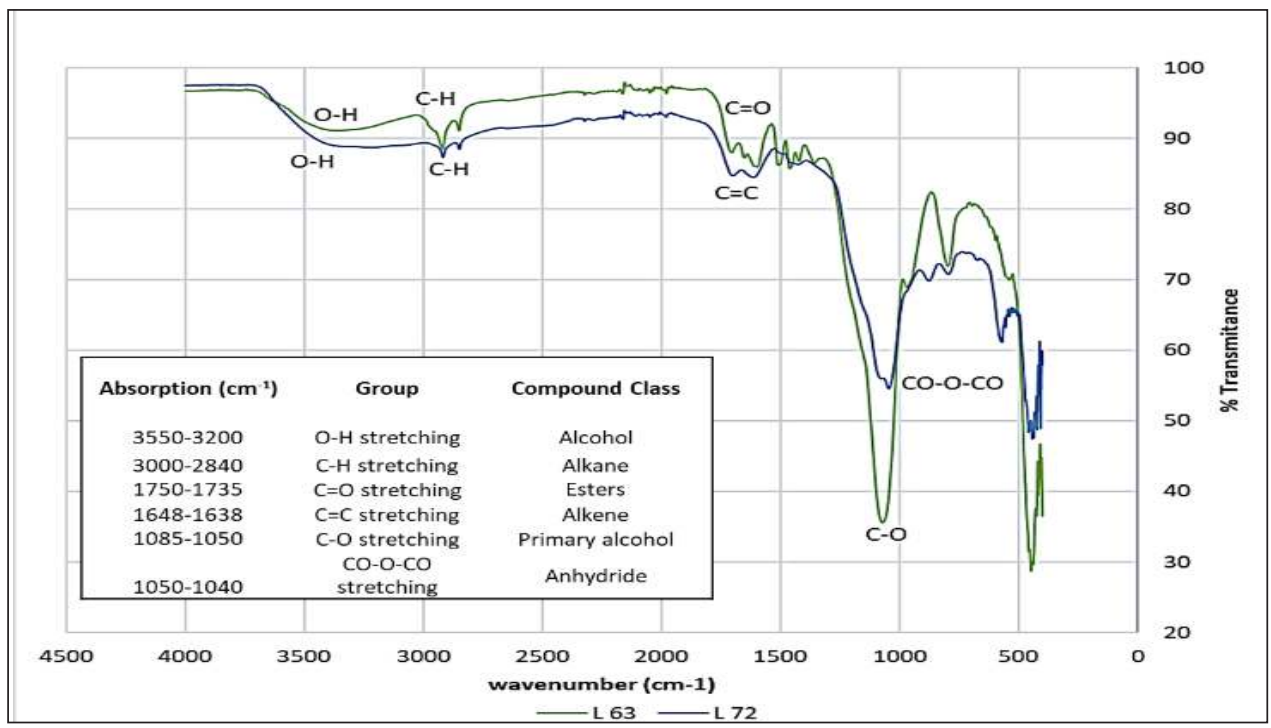

Figure 6: FT-IR spectrum showing the bond interlinkage comparison of the structural changes in lignin L-72 and L-63. 
Proposed structural integrity of the L-72 and L-63

The depolymerization rate is directly linked with the extent of lignin complexity. If it is too high, the bond breakage is very difficult, it dehydrates the reactive compound and condensed them more and more. This causes difficulty in further degradation of them into other products. Due to high complexity, the access of alkaline reagents becomes inaccessible and the free space and action site closes inside the complex. Guadix-Montero [19] and Shuai [20] explained the presence of inaccessible and unbreakable bonds formed due to condensation of reactive compounds in the lignin that occurred during the extraction process. A diagrammatic representation is proposed in Figure 7 to differentiate the structural integrity of the condensed and free-form lignin based on bond linkages between different precursors of lignin. There are chances of more number of unbreakable bond and inaccessible bond are present in the L-72, while a lesser number in L-63. The breakable bond can be present inside the vicinity of complex which are more accessible in L-63 than L72 because L-63 is more accessible from the surface also. Therefore, free-form lignin (L-63) showed higher depolymerization efficiency than condensed lignin (L-72).

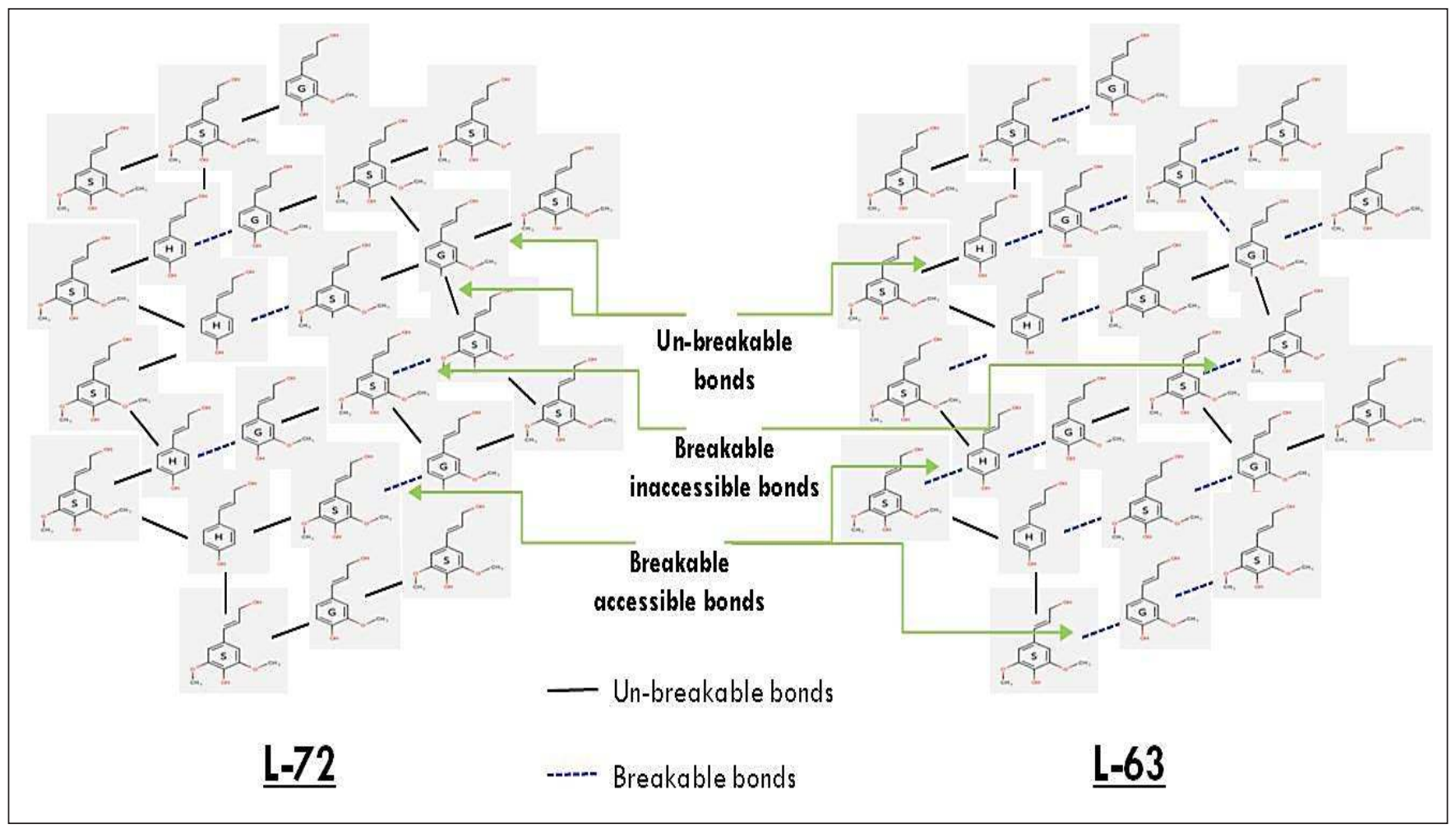

Figure 7: Proposed diagram of the structural integrity of the L-72 and L-63: Occurrence of inaccessible, breakable, and unbreakable bonds.

\section{CONCLUSION}

The selection of a better lignin substrate is the major key-base for de-polymerization studies. The effect of acid concentration change was found to directly affect the lignin structural changes. Similarly, further depolymerization efficiency was also affected. The availability of a free form of lignin groups is needed for the action of reactive functional groups of reagents. The use of the alkaline medium was very effective in depolymerizing nearly the maximum amount of L-63 and only one-third forL-72. So, it was concluded to use the free-form, soft, and light- brown lignin (L-63) for depolymerization and monolignol extraction. It also helps inthe purification and separation of phenolic monomers.

\section{ACKNOWLEDGEMENTS}

The authors are thankful to Bennett University for providing the necessary financial assistance to complete this study.

\section{CONFLICT OF INTEREST}

The authors declared no conflict of interest in this study.

\section{REFERENCES}

1. Li T, Takkellapati S. The current and emerging sources of technical lignins and their applications. Biofuels, Bioproducts and Biorefining. 2018 Sep;12(5):756-87.

2. Bruijnincx PC, Rinaldi R, Weckhuysen BM. Unlocking the potential of a sleeping giant: lignins as 
sustainable raw materials for renewable fuels, chemicals and materials. Green Chemistry. 2015;17(11):4860-1.

3. https://edu.rsc.org/feature/the-lignin-challenge/ 2000124.article (accessed on date 16/11/2020)

4. Yoon SY, Han SH, Shin SJ. The effect of hemicelluloses and lignin on acid hydrolysis of cellulose. Energy. 2014 Dec 1;77:19-24.

5. Sannigrahi P, Ragauskas AJ, Miller SJ. Effects of twostage dilute acid pretreatment on the structure and composition of lignin and cellulose in loblolly pine. BioEnergy Research. 2008 Dec 1;1(3-4):205-14.

6. Moxley G, Gaspar AR, Higgins D, Xu H. Structural changes of corn stover lignin during acid pretreatment. Journal of industrial microbiology \& biotechnology. 2012 Sep 1;39(9):1289-99.

7. Katahira R, Mittal A, McKinney K, Chen X, Tucker MP, Johnson DK, Beckham GT. Base-catalyzed depolymerization of biorefinerylignins. ACS Sustainable Chemistry \& Engineering. 2016 Mar 7;4(3):1474-86.

8. Shuai L, Saha B. Towards high-yield lignin monomer production. Green Chemistry. 2017;19(16):3752-8.

9. Svensson S. Minimizing the sulphur content in Kraft l i g n in. 2008 . h t t p : / / w w w. d i v a portal.org/smash/get/diva2:1676/FULLTEXT01.pdf (accessed on date 29/11/2020).

10. Sluiter A, Hames B, Ruiz R, Scarlata C, Sluiter J, Templeton D, Crocker DL. Determination of structural carbohydrates and lignin in biomass. Laboratory analytical procedure. 2008 Apr 25;1617(1):1-6.

11. Xu F, Sun JX, Sun R, Fowler P, Baird MS. Comparative study of organosolvlignins from wheat straw. Industrial crops and products. 2006 Mar 1;23(2):180-93.

12. Sannigrahi P, Kim DH, Jung S, Ragauskas A. Pseudolignin and pretreatment chemistry. Energy \& Environmental Science. 2011;4(4):1306-10.
13. Zhu W, Theliander $\mathbf{H}$. Precipitation of lignin from softwood black liquor: an investigation of the equilibrium and molecular properties of lignin. BioResources. 2015 Jan 29;10(1):1696-714.

14. Lourençon TV, Hansel FA, da Silva TA, Ramos LP, de Muniz GI, Magalhães WL. Hardwood and softwood kraftlignins fractionation by simple sequential acid precipitation. Separation and Purification Technology. 2015 Nov 5;154:82-8.

15. Domínguez-Robles J, Espinosa E, Savy D, Rosal A, Rodríguez Pascual A. Biorefinery process combining specel ${ }^{\circledR}$ process and selective lignin precipitation using mineral acids.

16. https://www.sigmaaldrich.com/technicaldocuments/articles/biology/ir-spectrum-table.html (Accessed on date 10/12/2020).

17. Remli NA, Shah UK, Mohamad R, Abd-Aziz S. Effects of chemical and thermal pretreatments on the enzymatic saccharification of rice straw for sugars production. BioResources. 2014;9(1):510-22.

18. Watkins D, Nuruddin M, Hosur M, Tcherbi-Narteh A, Jeelani S. Extraction and characterization of lignin from different biomass resources. Journal of Materials Research and Technology. 2015 Jan 1;4(1):26-32.

19. Kong F, Parhiala K, Wang S, Fatehi P. Preparation of cationic softwood kraft lignin and its application in dye removal. European Polymer Journal. 2015 Jun 1;67:33545.

20. Guadix-Montero S, Sankar M. Review on catalytic cleavage of $\mathrm{C}-\mathrm{C}$ inter-unit linkages in lignin model compounds: towards lignin depolymerisation. Topics in Catalysis. 2018 Apr 1;61(3-4):183-98. 